\title{
Radiographic Progression in Rheumatoid Arthritis: Does It Still Happen and Does It Matter?
}

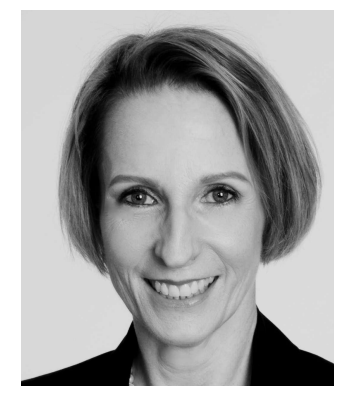

Radiographic progression (RP) has been an important objective outcome for assessing the comparative efficacy of therapies in clinical trials. It is being increasingly reported in observational studies of clinical care. RP is typically reported as a change in a modified version of the Sharp score (SS) ${ }^{1}$. Reported rates and extent of RP are much lower in patients with rheumatoid arthritis (RA) treated intensively, to a target of low disease activity or remission while receiving disease-modifying antirheumatic drugs (DMARD), including more effective doses of methotrexate (MTX) ${ }^{2}$. However, persisting swelling of $\geq 2$ (of 28) joints is associated with further RP (defined as a change $>0.5$ over 1 year) using SS scoring methods ${ }^{3}$. RP continues throughout the course of $\mathrm{RA}^{4}$, although less often for patients who are in remission more often ${ }^{5}$. RP reporting varies widely, using different cutoffs such as the smallest detectable change (SDC) to describe "rapid radiographic progression" (RRP) ${ }^{6}$. Thus rates of RP will vary depending on study design, patients studied, disease activity, and intensity of treatment interventions.

In this issue of The Journal, Ørnbjerg, et al publish additional results from the Danish Biologics Registry (DANBIO) on the rate and extent of RP in patients with serial hand radiographs using tumor necrosis factor (TNF) inhibitor (TNFi) therapy over an average of 1.5 years $^{7}$. Ørnbjerg, et al aimed to understand the effect on RP of drug switching and withdrawal. Prior analyses had shown that the extent and rate of RP dropped significantly once patients failing DMARD switched to TNFi therapy ${ }^{8}$. DANBIO patients had longstanding disease of 9 years, higher than usual rates of smoking (38\%), high C-reactive protein (CRP) levels for DMARD and steroid-treated patients, and $82 \%$ in this study had erosive disease. Patients had failed up to 6 DMARD (mean of 2.2), and started a TNFi [infliximab (IFX; 59\%), etanercept (ETN; 18\%), adalimumab (ADA; 23\%)]; $80 \%$ continued to take MTX (median dose 15 $\mathrm{mg} /$ weekly) but $60 \%$ still needed steroids, though in lower doses. The SS increased (by $>0$ ) in $29 \%$ who were classified as having RP, though over the study course this was on average only 1 point, mostly a new erosion. Only $4 \%$ had RRP defined as a change beyond twice the standard error or SDC.

Biologic switching was common, occurring in $30 \%$ of patients. Most switched to a second TNFi. Of those receiving initial IFX, ETN, and ADA $(33 \%, 20 \%$, and $27 \%$, respectively), switches were due either to loss of effect (in $52 \%, 42 \%$, and $39 \%$, respectively) or adverse events (36\%, $42 \%, 30 \%)$. Of those receiving TNFi monotherapy, fewer patients continued IFX (31\%) compared to ETN (73\%) and ADA (50\%). Only 10\% withdrew biologic therapy (reasons were not provided). Importantly, there was more RP in patients who switched or withdrew from biological therapy during this study. They had an independent greater risk for RP (OR 1.68 and 2.06, respectively, p < 0.001); however, it was not noted whether progressors had higher rates of disease activity. Not surprisingly, patients who continued biologic therapy throughout the study period - even if they had switched - had a 50\% lower odds of progression than those who withdrew TNFi.

Baseline factors associated with a risk for damage included rheumatoid factor (RF) positivity, high CRP, advanced age, and steroid use over the prior 2 years. Others have shown a relationship between RP, RF, and CRP ${ }^{9}$, but this is considered the first time that use of steroid was an independent predictor for RP.

So what does one make of these results? It is reassuring that RP is minimal once patients failing DMARD are treated with TNFi. Few had RP of concern. However, damage occurs more often if patients need to switch TNFi, possibly because of ongoing active synovitis. This study did not report whether switchers were TNFi nonresponders, TNFi nonadherent, or never achieved remission. Authors had previously reported that persistent disease activity is the main reason for ongoing structural damage ${ }^{10}$ and that remission rates were low in this registry ${ }^{11}$. Older age, low functional status, and concomitant prednisolone treatment

See Radiographic progression during anti-TNF treatment, page 2352

Personal non-commercial use only. The Journal of Rheumatology Copyright (c) 2014. All rights reserved. 
were negative predictors of clinical response and remission. It was previously reported that patients treated with IFX had lower rates of treatment response, disease remission, and interestingly, lower drug adherence. ADA-treated patients had the highest rates of treatment response and remission, and ETN-treated patients had the longest drug survival rates.

The finding that biologic therapy is protective of damage in clinical practice was also observed in the Swiss registry ${ }^{12}$, where a combination of achieving remission even once and taking biologics was most protective for damage. It may be possible to infer that more damage occurred in DANBIO because patients did not achieve remission as rapidly, because initial CRP elevations were associated with further damage.

Did these authors overclassify RP? This was an observational study performed as part of practice. Obtaining correctly positioned hand films may not always have been possible, causing more variability in SS. For randomized controlled trials (RCT), a change from 0 is considered reportable ${ }^{13}$. However, others suggest classification of RP in studies should be based on an increase in the SS at least beyond the $\mathrm{SDC}^{6,14,15}$. Thus, the surprisingly high rates of progression seen in DANBIO, albeit small in absolute change, may have been within the margin of error. Likely the authors chose this SS cutoff to classify RP to interpret findings in light of prior RCT of TNFi therapy. The authors specifically highlight that only $4 \%$ of patients were classified as "rapid progressors" defined using the SDC criterion. The main message from this and similar studies is that most patients taking TNFi therapies in settings of usual care are likely to be well protected from significant radiographic damage, as would have been predicted from clinical trials.

As is seen in other observational studies, use of glucocorticoids is a predictor for poor outcomes. Possibly the need for patients to persist with steroids is a surrogate marker for poor prognosis because these patients are also less likely to achieve sustained remission ${ }^{16}$. Interestingly, the Danish guidelines for biologic use include the continuous need for $>7.5 \mathrm{mg}$ prednisolone per day as an indication for biological treatment. In a recent analysis of ESPOIR, a study of patients with early RA, $40 \%$ were using steroids in the third year, and only $13 \%$ were taking biologics. Very little disease progression occurred as long as patients were in remission according to the Simplified Disease Activity Index or the Clinical Disease Activity Index. Again, in this study there was slightly more RP in those patients taking DMARD compared to those receiving biologics ${ }^{17}$.

In the DANBIO study, the initial damage level was an independent predictor of further damage, even in this population of high biologic users. This again suggests that efforts to use therapies to stringently control disease early and to reduce overall burden of synovitis should lower the risk of RP.
This study reported only slightly less RP than would be expected based on TNFi RCT. A systematic review examining RP over 1 year based on SS in TNFi-treated patients from RCT noted increases in SS ranging from $1.1-2.8$ in studies published after $2002^{18}$. Only the ASPIRE trial ${ }^{19}$ had very high rates of progression. In MTX-naive patients treated with TNFi in RCT, RP was only slightly higher, ranging from $1.37-5.70^{18}$. It is quite possible that the degree of RP reported in DANBIO could easily have fallen in this range because DANBIO scores were based only on hand radiographs and did not include radiographic changes in the feet. This may have resulted in an underestimate of erosiveness because others have shown that failing to add scores from serial foot radiographs can result in missing up to $30 \%$ of additional erosive disease ${ }^{20}$.

Putting aside issues of adjudication of damage progression, let us consider the more important question: Why should health providers continue to be concerned about halting damage? The reason is simple. Less damage is associated with better function. Bombardier, et al summarized the literature on the relationship between RP and function $^{21}$. Of 23 studies addressing this question, almost all showed a statistically significant relationship between worsening damage and decline in function. This relationship was strongest in the more methodologically sound studies. More importantly, Navarro-Compán, et al have clearly demonstrated that functional disturbances as assessed using hand function questions from the Arthritis Impact Measure Questionnaire are clearly affected by damage progression ${ }^{22}$. Thus, it remains imperative for rheumatologists to be certain that their patients with RA are not damaging their joints. The ongoing use of glucocorticoids seems insufficient to protect joints and could be an indicator to consider biologic therapy. Intensification of treatment to achieve very low levels of disease activity should continue to be a priority in aiming to prevent RP. However, when that is not possible, patients are far less likely to have significant RP when using TNFi.

VIVIAN P. BYKERK, MD,

Department of Rheumatology,

Hospital for Special Surgery,

535 East 70th St.,

New York, New York 10021, USA

Address correspondence to Dr. Bykerk. E-mail: bykerkv@hss.edu

\section{REFERENCES}

1. van der Heijde DM. Plain X-rays in rheumatoid arthritis: overview of scoring methods, their reliability and applicability. Baillieres Clin Rheumatol 1996;10:435-53.

2. Rezaei H, Saevarsdottir S, Forslind K, Albertsson K, Wallin H, Bratt J, et al. In early rheumatoid arthritis, patients with a good initial response to methotrexate have excellent 2-year clinical outcomes, but radiological progression is not fully prevented: data from the methotrexate responders population in the SWEFOT trial. Ann Rheum Dis 2012;71:186-91.

3. Aletaha D, Smolen JS. Joint damage in rheumatoid arthritis progresses in remission according to the Disease Activity Score in

Personal non-commercial use only. The Journal of Rheumatology Copyright @ 2014 . All rights reserved. 
28 joints and is driven by residual swollen joints. Arthritis Rheum 2011;63:3702-11.

4. Hulsmans HM, Jacobs JW, van der Heijde DM, van Albada-Kuipers GA, Schenk Y, Bijlsma JW. The course of radiologic damage during the first six years of rheumatoid arthritis. Arthritis Rheum 2000;43:1927-40.

5. Lillegraven S, Prince FH, Shadick NA, Bykerk VP, Lu B, Frits ML, et al. Remission and radiographic outcome in rheumatoid arthritis: application of the 2011 ACR/EULAR remission criteria in an observational cohort. Ann Rheum Dis 2012;71:681-6.

6. Bruynesteyn K, Boers M, Kostense P, van der Linden S, van der Heijde D. Deciding on progression of joint damage in paired films of individual patients: smallest detectable difference or change. Ann Rheum Dis 2005;64:179-82.

7. Ørnbjerg L, Bøyesen P, Tarp U, Graudal N, Kollerup G, Jensen D, et al. Which factors influence radiographic progression during treatment with tumor necrosis factor inhibitors in clinical practice? Results from 930 patients with rheumatoid arthritis in the nationwide Danish DANBIO registry. J Rheumatol 2014;41:2352-60.

8. Ornbjerg LM, Ostergaard M, Bøyesen P, Krogh NS, Thormann A, Tarp U, et al. Impact of tumour necrosis factor inhibitor treatment on radiographic progression in rheumatoid arthritis patients in clinical practice: results from the nationwide Danish DANBIO registry. Ann Rheum Dis 2013;72:57-63.

9. Visser K, Goekoop-Ruiterman YP, de Vries-Bouwstra JK, Ronday HK, Seys PE, Kerstens PJ, et al. A matrix risk model for the prediction of rapid radiographic progression in patients with rheumatoid arthritis receiving different dynamic treatment strategies: post hoc analyses from the BeSt study. Ann Rheum Dis 2010;69:1333-7.

10. Welsing PM, Landewe RB, van Riel PL, Boers M, van Gestel AM, van der Linden $\mathrm{S}$, et al. The relationship between disease activity and radiologic progression in patients with rheumatoid arthritis: a longitudinal analysis. Arthritis Rheum 2004;50;2082-93.

11. Hetland ML, Christensen IJ, Tarp U, Dreyer L, Hansen A, Hansen IT, et al. Direct comparison of treatment responses, remission rates, and drug adherence in patients with rheumatoid arthritis treated with adalimumab, etanercept, or infliximab: results from eight years of surveillance of clinical practice in the nationwide Danish DANBIO registry. Arthritis Rheum 2010;62:22-32.

12. Ciubotariu E, Gabay C, Finckh A. Joint damage progression in patients with rheumatoid arthritis in clinical remission. Do biologics perform better than synthetic antirheumatic drugs? J Rheumatol 2014;41:1576-82.
13. van der Heijde D, Simon L, Smolen J, Strand V, Sharp J, Boers M, et al. How to report radiographic data in randomized clinical trials in rheumatoid arthritis: Guidelines from a roundtable discussion. Arthritis Rheum 2002;47:215-8.

14. Navarro-Compán V, van der Heijde D, Ahmad HA, Miller CG, Wolterbeek R, Landewe R. Measurement error in the assessment of radiographic progression in rheumatoid arthritis (RA) clinical trials: the smallest detectable change (SDC) revisited. Ann Rheum Dis 2014;73:1067-70.

15. Boini S, Guillemin F. Radiographic scoring methods as outcome measures in rheumatoid arthritis: properties and advantages. Ann Rheum Dis 2001;60:817-27.

16. Kuriya B, Xiong J, Boire G, Haraoui B, Hitchon C, Pope J, et al. Earlier time-to-remission predicts sustained clinical remission in early rheumatoid arthritis (ERA) - Results from the Canadian Early Arthritis Cohort (CATCH). J Rheumatol 2014;41:2161-6.

17. Ruyssen-Witrand A, Guernec G, Nigon D, Tobon GJ, Jamard B, Rat A, et al. Aiming for SDAI remission versus low disease activity at 1 year after inclusion in ESPOIR cohort is associated with better 3-year structural outcomes. Ann Rheum Dis 2014;2014:1-8.

18. Rahman MU, Buchanan J, Doyle MK, Hsia EC, Gathany T, Parasuraman S, et al. Changes in patient characteristics in anti-tumour necrosis factor clinical trials for rheumatoid arthritis: results of an analysis of the literature over the past 16 years. Ann Rheum Dis 2011;70:1631-40.

19. Smolen JS, Van Der Heijde DM, St Clair EW, Emery P, Bathon JM, Keystone E, et al. Predictors of joint damage in patients with early rheumatoid arthritis treated with high-dose methotrexate with or without concomitant infliximab: results from the ASPIRE trial. Arthritis Rheum 2006;54:702-10.

20. Knevel R, Kwok KY, de Rooy DP, Posthumus MD, Huizinga TW, Brouwer E, et al. Evaluating joint destruction in rheumatoid arthritis: is it necessary to radiograph both hands and feet? Ann Rheum Dis 2013;72:345-9.

21. Bombardier C, Barbieri M, Parthan A, Zack DJ, Walker V, Macarios D, et al. The relationship between joint damage and functional disability in rheumatoid arthritis: a systematic review. Ann Rheum Dis 2012;71:836-44.

22. Navarro-Compán V, Landewe R, Provan SA, Odegard S, Uhlig T, Kvien TK, et al. Relationship between types of radiographic damage and disability in patients with rheumatoid arthritis in the EURIDISS cohort: a longitudinal study. Rheumatology 2014 Jul 26 (E-pub ahead of print).

J Rheumatol 2014;41:2337-9; doi:10.3899/jrheum.141133 